\title{
RESISTÊNCIA NO TRABALHO DOCENTE: UM ESTUDO SOBRE SUAS MANIFESTAÇÕES E MOTIVAÇÕES
}

\author{
Nathália Cristina Amorim Tamaio de Souza ${ }^{1}$ \\ Flávia Graziela Moreira Passalacqua²
}

\begin{abstract}
RESUMO: Este artigo tem como objetivo explicitar, discutir e problematizar a resistência docente, focalizando aquela que se manifesta face às ações de sujeitos externos em âmbito pedagógico. Para seu desenvolvimento, lançou-se mão do cotejo de dados provenientes de duas pesquisas produzidas individualmente pelas autoras. A apreciação dos relatos que compõem as pesquisas mencionadas se apoiou nas orientações da análise de conteúdo e permitiu verificar que a resistência dos professores pode ter pelo menos duas motivações: o receio de críticas, quando se trata da resistência às ações do pesquisador; e o descrédito, quando o alvo da postura resistente é o licenciando/estagiário. Todavia, ainda que a prática da resistência represente um empecilho para os agentes que adentram a sala de aula, os indicativos deste estudo revelam que a inflexibilidade dos professores é justificável e que tende a ser revertida com condutas diplomáticas e aproximações graduais que visem à valorização do trabalho docente.
\end{abstract}

Palavras-chave: Resistência docente. Formação de professores. Educação Básica.

\section{RESISTANCE IN TEACHING WORK: A STUDY OF ITS MANIFESTATIONS AND MOTIVATIONS}

ABSTRACT: This paper aims to explain, discuss, and problematize teacher resistance, focusing on the one that manifests itself to the actions of external

\footnotetext{
${ }^{1}$ Pedagoga. Mestre em Educação Escolar pela UNESP. Doutoranda em Educação pela UNICAMP. Docente da Educação Básica (anos iniciais do Ensino Fundamental) no SESI de Araraquara. E-mail: nathytamaio@hotmail.com

2 Pedagoga. Doutora em Educação Escolar pela UNESP. Pesquisadora de pós-doutorado na UNESP Araraquara. E-mail: flaviagraziela@hotmail.com
} 
subjects in pedagogical scope. For its development, it was used the collation of data coming from two research produced individually by the authors. The appreciation of the reports that make up the mentioned research was based on the guidelines of the content analysis and allowed to verify that the resistance of the professors can have at least two motivations: the fear of criticism, when it comes to resistance to the actions of the researcher; and discredit, when the target of sturdy posture is the ungraduated/trainee. However, although the practice of resistance represents an obstacle to the agents entering the classroom, the indicatives of this study reveal that the inflexibility of teachers is justifiable and that it tends to be reversed through diplomatic conduct and gradual approximations aimed at valorizing the teaching work.

Keywords: Teaching resistance. Teacher training. Basic Education.

\title{
RESISTENCIA EN EL TRABAJO DOCENTE: UN STUDIO SOBRE SUS MANIFESTACIONES Y MOTIVACIONES
}

\begin{abstract}
RESUMEN: Este artículo tiene como objetivo explicitar, discutir y problematizar la resistencia docente, enfocando aquella que se manifiesta frente a las acciones de sujetos externos al ámbito pedagógico. Para su desarrollo, se echó mano del cotejo de datos provenientes de dos investigaciones producidas individualmente por las autoras. La apreciación de los relatos que componen las investigaciones mencionadas se apoyó en las orientaciones del análisis de contenido y permitió verificar que la resistencia de los profesores puede tener por lo menos dos motivaciones: el temor de críticas, cuando se trata de la resistencia a las acciones del investigador; y el descrédito, cuando el objetivo de la postura resistente es el licenciamiento/pasante. Sin embargo, aunque la práctica de la resistencia represente un obstáculo para los agentes que entran en el aula, los indicativos de este estudio revelan que la inflexibilidad de los profesores es justificable y que tiende a ser revertida con conductas diplomáticas y aproximaciones graduales que apunte a la valorización del trabajo docente.
\end{abstract}

Palabras clave: Resistencia docente. Formación del profesorado. Educación Básica.

O presente texto pretende discutir a manifestação e as possíveis motivações da resistência no trabalho de professores que atuam nos anos iniciais do ensino 
fundamental, focalizando um aspecto bastante específico: aquela que se expressa como reação às ações realizadas por sujeitos externos em âmbito pedagógico. A idealização do tema eleito para discussão foi impulsionada pelas interlocuções entre duas pesquisas produzidas individualmente pelas autoras do artigo que ora se inscreve. Uma delas, doravante denominada P1, permitiu capturar as impressões de uma pesquisadora de Pós-Graduação stricto sensu sobre sua atuação em salas de aula e demais ambientes escolares, durante o desenvolvimento de pesquisa de campo com docentes, enquanto a outra, P2, deu voz a licenciandas de um curso de Pedagogia, identificando suas percepções quanto ao momento de inserção nas escolas na condição de aprendizes da docência. Ambas as pesquisas foram realizadas nas mesmas escolas e em momentos correspondentes, abarcando episódios ocorridos entre os anos de 2010 e 2014.

As escolas selecionadas se situam em regiões periféricas de um município do interior paulista e contam com professores que, em sua maioria, são experientes. São poucos os iniciantes. No entanto, cabe ressaltar que, em relação ao enfoque dado no presente trabalho - a resistência docente -, não houve distinções expressivas entre a postura dos que estão há mais de vinte anos atuando profissionalmente e dos que ingressaram mais recentemente na profissão, conforme revelaram as informações das pesquisas.

Ao cotejarmos os dados das referidas pesquisas, pudemos averiguar que a resistência docente se apresentou tanto de maneira explícita como implícita, sendo entendida em ambos os casos como "estratégias de contorno a métodos, medidas e projetos institucionais que visam promover mudanças na prática pedagógica" (SCANFELLA, 2013, p. 49-50). A resistência explícita é configurada por atitudes mais incisivas, demonstradas pelos professores por meio de seus discursos e posturas no dia 
a dia, podendo indicar os aspectos "a que" resistem, e o "porquê" e "como/de que forma" resistem. A resistência implícita, por sua vez, tende a silenciar-se nas manifestações e comportamentos dos professores devido aos ensaios de reajustamento e adaptações às mudanças oriundas das deliberações oficiais. Portanto, sua identificação pode ser dificultada mediante os discusos aparentemente favoráveis (SCANFELLA, 2013).

Considerando tais definições, compreendemos que os professores têm vetado influências no recinto da sala de aula por temerem que elas venham a prejudicar sua desenvoltura ou interferir negativamente na rotina de suas aulas. Acrescentamos ainda, a título de hipótese, que a resistência às ações em âmbito pedagógico é uma maneira tangível de os professores esboçarem suas indignações mais profundas, dado que na sala de aula eles têm uma força de expressão maior, que pode ser resultante da pretensa sensação de posse/domínio do espaço e da turma.

É válido antecipar que, ao analisarmos a origem da resistência docente nas pesquisas por nós empreendidas, desvendamos duas causas potenciais: no caso da P1, trata-se de uma resistência revestida de receio às observações e às possíveis críticas da pesquisadora, compreendida pelos próprios professores como autoridade intelectual. Na P2, a resistência aparece impregnada do sentimento de descrédito e insegurança quanto ao trabalho das licenciandas.

O referencial adotado se consubstancia por obras relativamente recentes, preponderantemente nacionais, que fundamentaram as duas pesquisas e, portanto, dialogam entre si. Buscamos respaldo em textos que concebem a docência como algo que se edifica na indissociabilidade entre teoria e prática, que atribuem cara importância à ideia de formação entre pares e que defendem o estreitamento da relação entre universidade e escola (GARRIDO; CARVALHO, 1999; GATTI, 2000; GATTI 
et al., 2013; GATTI; BARRETTO, 2009; GUARNIERI, 2018; PIMENTA, 2001).

Delimitados o objeto, a hipótese e o referencial da investigação que propomos desenvolver, chamamos atenção para a estrutura que lhe dará sustentação. Na sequência desta Introdução, são delineados os Caminhos metodológicos para análise de dados, que explicita os recursos utilizados e o tratamento dado à descrição e análise dos dados deste estudo. Na próxima seção, intitulada Resistência docente: o receio de críticas, tecemos uma discussão embasada em notas de campo de uma pesquisadora sobre a postura resistente das professoras ${ }^{3}$ a sua presença em sala de aula. Na seção seguinte, Resistência docente: o descrédito, analisamos relatos de licenciandas relacionados às dificuldades que enfrentaram ao se deparar com professoras inflexíveis. Por fim, apresentamos nas Considerações finais uma síntese do problema discutido ao longo do artigo e apontamos algumas possibilidades para sua minimização.

\section{Caminhos metodológicos para análise dos dados}

A metodologia que subsidia esta investigação consiste na realização de estudo de natureza empírica de abordagem qualitativa. Para a constituição dos dados recorreu-se à análise de diferentes fontes, sendo elas provenientes de entrevistas com sujeitos participantes das pesquisas de $\mathrm{P} 1$ e $\mathrm{P} 2$. Os sujeitos pesquisados integram uma pesquisa de Mestrado Acadêmico, no caso da P1, e um grupo de licenciandas de um curso de Pedagogia em período de iniciação à docência, no caso da P2. Em ambos os

3 Ao nos referirmos diretamente aos sujeitos da pesquisa, empregaremos o substantivo "professora(s)", no feminino, pelo fato de todas as envolvidas serem mulheres. O mesmo se aplica ao substantivo "licencianda(s)". 
estudos, foram realizadas observações e coleta de dados com sujeitos envolvidos em escolas de Educação Básica situadas em regiões periféricas de um município do interior paulista.

A técnica escolhida para a realização da análise dos dados é a Análise de Conteúdo, segundo as diretrizes de Bardin (2011). Inicialmente, estruturou-se a fase que a autora denomina como pré-análise, ou seja, a seleção e organização do material selecionado. Nessa pré-análise efetuada foram consideradas diferentes operações, as quais contemplaram: amostragem, isto é, um recorte metodológico baseado em critérios bem definidos do material de análise; pertinência, caracterizada pela escolha das fontes de informação que corresponderam ao objetivo da análise; e sistematização, que consistiu na disposição metódica do material a analisado.

Assim procedendo, calculamos que, em termos de frequência, na pesquisa $\mathrm{P} 1$, a questão da resistência à pesquisadora pôde ser percebida em $70 \%$ das notas de campo, enquanto na $\mathrm{P} 2$, os relatos que mencionaram de forma explícita ou nas entrelinhas a percepção da resistência docente, perfizeram cerca de $60 \%$ do teor total abordado. Após identificarmos as passagens que versavam sobre a resistência em nossas pesquisas, elaboramos uma legenda designando uma cor para cada aspecto suscitado (manifestações em amarelo e motivações em vermelho); cores essas cuja correspondência apareceu no tom de realce dos fragmentos extraídos.

A segunda fase se referiu ao momento de exploração do material. Segundo Bardin (2011), ela costuma ser longa e trabalhosa, pois incide em operações de codificação. Pode-se dizer que, no caso do presente estudo, essa fase correspondeu à interlocução e análise dos dados empíricos. Desse modo, depois de dispormos os fragmentos de texto por cores e respectivas legendas, cotejamos as informações com o intuito de verificar se as expressões de resistência eram ou não da mesma natureza 
nos dois trabalhos.

Ao verificarmos as discrepâncias com relação às origens da resistência docente nas pesquisas, chegamos à terceira fase do processo: o tratamento dos dados. Para tanto, elaboramos dois eixos de análise: Resistência docente: o receio de críticas (proveniente dos dados da P1); e Resistência docente: o descrédito (construído a partir dos dados da P2). Na seção a seguir, explicitaremos as especificidades e o desfecho de cada um deles.

\section{Resistência docente: o receio de críticas}

Se pensarmos no termo resistência associado à imagem do professor, é muito provável que nos venha à mente a ideia de oposição ao uso de tecnologias, às medidas e políticas institucionais, às exigências dos processos de formação permanente, às reformas escolares, ou a quaisquer ações que representem contradições em relação ao ideal tencionado pela categoria (FERNANDES, 2008; SILVA JÚNIOR; FERRETI, 2004). O que pouco se problematiza, e que colocamos em pauta nesta seção, é a questão da resistência ao sujeito que realiza ações no interior das salas de aula - neste caso, uma pesquisadora.

Em geral, o pesquisador não possui controle dos efeitos de sua presença no campo em que sua pesquisa se desenvolve, preocupando-se somente com a qualidade dos registros de observação e sua posterior reflexão, com o intuito de entender a realidade social estudada e suas particularidades por meio do movimento que se faz do geral (macro) para o específico (micro), ou vice-versa, permitindo localizar e legitimar os indicativos apontados no estudo. As observações nos ambientes escolares, no entanto, exprimem a ideia de uma investigação que segue caminhos mais 
maleáveis, ao mesmo tempo em que a presença do pesquisador como observador provoca súbitas reações dos sujeitos envolvidos devido às obliquidades de suas posições teóricas e, também, à posição de poder que lhe é conferida (TURA, 2003).

No caso da pesquisa $\mathrm{P} 1$, cujo cerne incidiu sobre a identificação das necessidades formativas de professoras dos anos iniciais do ensino fundamental por meio de observações das aulas e dos demais ambientes escolares (biblioteca, sala de vídeo, informática, entre outros), de registros do diário de campo e de entrevistas, pode-se dizer que as reações das professoras às ações da pesquisadora em sala de aula foram, especialmente no início, aversivas. Por essa razão, embora o tema da resistência docente não tenha sido conjecturado no momento da elaboração inicial da investigação em questão, sua manifestação provocou questionamentos suscetíveis de análise e impossíveis de serem ignorados.

De acordo com o conteúdo das notas de campo registradas durante a pesquisa, as docentes se mostraram resistentes ao se sentirem vigiadas por uma representante da academia, ainda que a pesquisadora tenha assumido uma atitude cortês. Uma nota corrobora essa observação.

A imprevisibilidade de reações dos sujeitos exigiu-me uma postura firme $e$ segura, mas, ao mesmo tempo, compreensiva, pois a posição e imagem de poder supostamente atribuídas a mim poderiam gerar situações inusitadas $e$ imprevisíveis. Por inúmeras vezes, questionaram minhas reais intenções dentro da escola e o teor da pesquisa por mim realizada, evidenciando os receios que sentiam quanto a minha presença e minhas conclusões que, a seus olhos, poderiam culpabilizá-las pelos problemas educacionais (Nota de campo, P1).

Cada uma das professoras observadas apresentou uma forma diferente de lidar com as situações que fogem à rotina da escola, isto é, com o comparecimento frequente da pesquisadora ao ambiente de sala de aula. As experientes manifestaram 
comportamentos mais engessados, conservadores e imutáveis, enquanto as iniciantes na profissão foram um pouco mais afáveis, embora também rejeitassem tacitamente a presença de uma 'estranha' em seu espaço.

Compreendemos, pois, que as diferentes gradações da resistência sejam decorrentes do sentimento de posse sobre a escola e os alunos, fortalecido com o passar dos anos na profissão, e da criação de uma hierarquia interna que enaltece os professores veteranos e seus pontos de vista, não raras vezes obsoletos e contrários a mudanças (HUBERMAN, 2000). Além disso, características como a falta de expectativa, o distanciamento afetivo, o conservadorismo dos padrões adquiridos ao longo do exercício da função pedagógica e mesmo a redução do investimento na carreira (HUBERMAN, 2000), podem ser consideradas razões para a acolhida à pesquisadora nas salas de aula ter sido feita sob a forma de negação.

A despeito disso, esclarecemos que não há a intenção de anular e tampouco de destacar em demasia as reações observadas e sentidas, mesmo porque é por meio dessas nuanças que os sujeitos se revelam, e suas resistências podem ser a maneira que elas (professoras/sujeitos da pesquisa) encontram para dizer/mostrar que existem e têm voz ativa. O desafio, no entanto, é trabalhar com essa pluralidade de reações, atitudes e diferenças entre os sujeitos, sem que se obtenha um caráter de denúncia e, simultaneamente, buscar a melhor forma de desenvolver a pesquisa sem que essas questões a inviabilizem.

Outro aspecto que pode ser apontado como motivador da resistência docente é a forte cisão entre conhecimento teórico e conhecimento prático, há tempos instaurada na realidade educacional. O registro abaixo traduz perfeitamente essa questão. 
que não pode ser descartada [...]. Eu era tratada como "a teórica lá da faculdade" e ser vista dessa forma me incomodava, pois a reação dos sujeitos sugeria principalmente rejeição, exterioridade e desconfiança (Nota de campo, P1).

Cabe lembrar que por muito tempo os professores foram compreendidos pelos teóricos da Educação como seres abstratos e homogêneos, e o exercício da função pedagógica era visto como uma mera instrumentalização, afastando a pesquisa acadêmica da prática dos professores e, consequentemente, desvalorizando o conhecimento desses profissionais (GATTI, 1996). Além disso, uma parcela considerável de pesquisadores que realiza seus estudos dentro da comunidade escolar se insere nas salas de aula, coleta os dados necessários e deixa os professores sem o devido retorno dos resultados, restringindo suas descobertas às bibliotecas.

É justamente essa ausência de conexão entre os indicadores das pesquisas acadêmicas e os problemas concretos que assolam os professores que os distancia da teorização. Nessa perspectiva podemos situar a seguinte percepção.

Parte da resistência que eu sofri se deu pelo fato de as professoras julgarem, tanto a minha presença quanto a minha pesquisa, pouco expressivas em relação à resolução das situações problemáticas enfrentadas cotidianamente no ambiente escolar (Nota de campo, P1).

A necessidade de resoluções rápidas, produto de uma sociedade que vive constantes transformações (TEDESCO, 2007), pode ser também um dos fatores responsáveis pela resistência de professores diante das propostas de colaboração. Por vivenciarem os desafios presentes na Educação e sentirem seus reflexos na sociedade, é presumível que os docentes, pautados no pensamento racionalista, que tudo descreve, explica e resolve (PESSANHA, 1997), resistam à presença de pesquisadores em sala de aula simplesmente porque necessitam visualizar e sentir os efeitos de suas 
pesquisas na ação imediata.

Sendo assim, por mais que o pesquisador redirecione o foco de análise e se aproxime dos professores e da realidade cotidiana deles, sua imagem acaba sendo inevitavelmente associada à de um representante da universidade que se instala nas salas de aula apenas para extrair elementos pertinentes à elaboração de seu trabalho em benefício próprio. Dessa forma, quando uma investigação é iniciada na instituição escolar, os sujeitos começam a elaborar uma interpretação sobre a presença constante do pesquisador. Essa presença, mesmo que incômoda, exige dos professores a abertura de um espaço em suas rotinas para acolhê-lo e a maneira como eles realizam essa tarefa dentro da escola pode revelar a forma como eles enxergam o mundo e o cenário em que exercem a função pedagógica (CARVALHO, 2003).

Nessas condições, parece ser uma atitude perspicaz o pesquisador estabelecer uma relação compreensiva e amigável com os professores. Pouco se fala a esse respeito em pesquisas científicas, mas os docentes necessitam ter com quem desabafar sobre as suas angústias diárias e os dissabores sentidos pelo desprestígio da profissão, acentuado no caso de professores dos anos iniciais do ensino fundamental (GATTI, 2013). E encontrar uma pessoa externa à escola disposta a lhes ouvir, pode ser um alento. Pensando nisso, e após vivenciar um período inicial de forte resistência, a pesquisadora da P1 sabiamente conduziu suas práticas por esse caminho e o resultado foi bastante promissor.

A postura e a linguagem adequadas dentro das escolas e o trato gentil com as professoras, demais funcionários e alunos foram fundamentais para manter-me próxima dos sujeitos e inserida no contexto pesquisado [...]. Aos poucos minha presença rotineira pelos corredores se tornou praticamente invisivel aos olhos dos sujeitos e isso fez com que diminuísse a distância entre a figura de pesquisadora (autoridade, oriunda da Universidade, avaliadora das práticas etc.) e a figura comum (confidente, compreensiva, assistente para os assuntos da sala de aula etc.) atribuída a minha pessoa. Desta forma, 
pude ir percebendo as particularidades do cotidiano das instituições, as emoções dos sujeitos, as hierarquias presentes e as necessidades formativas (Nota de campo, P1).

Diante do exposto ao longo desta seção, podemos inferir que as resistências observadas e sentidas durante o percurso da pesquisa aqui discutida expressam a importância de se aproximar a teoria (suposto atributo dos pesquisadores) da prática (suposto atributo dos professores), ressaltando o valor e o grau de importância dado à participação de cada um dos professores nas pesquisas, das quais eles serão os proponentes dos resultados alcançados e colaboradores no aperfeiçoamento dos programas formativos futuros. Uma vez assumido esse compromisso, mais do que minimizar os sinais de resistência provenientes do corpo docente e direcionados ao pesquisador, poderão ser conjecturadas ações de formação continuada consistentes com a colaboração da Universidade, sem que se esbarre nos receios, nos medos e nas desconfianças.

\section{Resistência docente: o descrédito}

Do mesmo modo que a pesquisa P1, a P2 não teve o intuito de projetar o tema da resistência docente como objeto analítico. Seu objetivo residiu na identificação de elementos que constituem o preparo prático de futuras professoras para o exercício da profissão. Entretanto, ao investigar o processo de inserção à docência, vivenciado durante a formação inicial, constatou-se indícios recorrentes de inflexibilidade por parte de professoras que receberam licenciandas em suas salas de aula, e isto possibilitou o estudo da resistência docente enquanto um recorte focal bastante rico. 
RESISTÊNCIA NO TRABALHO DOCENTE: UM ESTUDO SOBRE SUAS MANIFESTAÇÕES E MOTIVAÇÕES

N. C. A. T. DE SOUZA

F. G. M. PASSALACQUA

Não é raro, tampouco descoberta recente, que significativa parcela dos professores em exercício sinta-se incomodada com licenciandos, sejam eles estagiários ou participantes de programas institucionais, ocupando o espaço em que suas aulas são ministradas. Mas, o problema se institui mais seriamente quando os incômodos se transformam em negligências.

Estudos, como o de Guarnieri (2018), evidenciam que a prática na formação inicial tem sofrido forte esvaziamento em decorrência das barreiras impostas pelos professores das escolas de Educação Básica. A autora destaca que são cada vez mais insólitos os momentos de intervenção e interação dos estudantes de licenciatura com as situações de ensino, com ressalva às solicitações, por parte dos professores, para que eles acompanhem um ou outro aluno que apresenta maiores dificuldades. 0 desenrolar desse tipo de atividade habitualmente segue o padrão em que o licenciando e o aluno (ou um pequeno grupo de alunos) se acomodam em carteiras no fundo da sala de aula, isolados do restante da turma, enquanto o professor prossegue com os afazeres cotidianos, conduzindo a parcela majoritária de alunos cujos ritmos de aprendizagem são mais ou menos homogêneos. Tal dinâmica, emblemática da resistência, é corroborada pelos depoimentos abaixo:

No início era uma coisa de ficar observando e intervir com alguns alunos que tinham mais dificuldades. Aplicar alguma atividade efetivamente, só quando a professora pedia mesmo e só se fosse elaborada por ela. (Licencianda A, P2).

Ela queria que eu ficasse com um, dois ou três alunos que tinham mais dificuldades para ajudá-los. Mas a impressão que eu tinha é que eu era uma auxiliar que cuidava dos que ela considerava "alunos-problema" enquanto ela seguia com o restante turma, sabe? (Licencianda $B, P 2$ ).

A forma com que os licenciandos são inseridos nas escolas define em grande medida como será o nível de sua aprendizagem acerca dos elementos que constituem 
a docência. Portanto, deve-se observar, inicialmente, como se efetiva a relação da universidade com o grupo de escolas da rede de ensino que recebem seus alunos, e se a inserção dos mesmos ocorre de maneira orientada e planejada ou não.

Já se sabe pelas pesquisas (GATTI, 2000; GATTI; BARRETO, 2009; MARCELO 1999; PIMENTA, 2001) que os futuros professores que têm a oportunidade de vivenciar de forma orgânica as múltiplas facetas pedagógicas costumam sofrer menos impactos ao iniciarem a carreira profissionalmente. Isso ocorre porque podem ser capazes de estabelecer atitudes e estratégias adequadas a determinado contexto por possuírem conhecimentos práticos consideravelmente superiores àqueles que não tiveram um contato estreito e ativo com o manejo de situações reais em sala de aula durante a realização do estágio.

Se o aprendiz-professor tem a possibilidade de elaborar atividades em parceria com o professor responsável pela sala de aula e aplicá-las conjuntamente, está aprendendo tanto a conciliar o conhecimento específico do conteúdo aos meios mais adaptados de transmiti-lo à turma - desenvolvendo o que Gauthier et al. (1998) denomina como gestão de classe e da matéria - quanto a desenvolver, implicitamente, a socialização profissional e estratégias de autonomia para sua atuação futura. Nesse sentido, Tardif (2002) reforça que a interação de licenciandos em sala de aula com os alunos e o professor é um elemento estruturante da constituição da epistemologia da prática docente.

Os estagiários que, por sua vez, simplesmente observam as práticas dos professores sem poderem intervir tendem a trilhar um dos caminhos opostos entre si: repetir acriticamente os mesmos procedimentos utilizados pelo professor observado, desconsiderando as particularidades de sua turma; ou condenar a postura do professor sem qualquer fundamentação, alegando que durante o estágio aprendeu somente o 
RESISTÊNCIA NO TRABALHO DOCENTE: UM ESTUDO SOBRE SUAS MANIFESTAÇÕES E MOTIVAÇÕES

N. C. A. T. DE SOUZA

F. G. M. PASSALACQUA

que não se deve fazer em sala de aula (SOUZA, 2014). Verifica-se, pois, que este caso tem sido bastante recorrente, uma vez que:

[...] as professoras resistem em aceitar que os estagiários possam dar aulas para suas turmas ou que desenvolvam atividades trazidas por eles a partir do que estão aprendendo no curso e do que vivenciam durante esse contato com as professoras (GUARNIERI, 2018, p. 102).

Os relatos abaixo expressam as percepções de licenciandas sobre isso.

Foi bem difícil ser recebida nas salas de aula pelas professoras. E a dificuldade era justamente ser reconhecida como futura professora. Elas não nos enxergavam dessa maneira. Olhavam para nós só como alunas de faculdade. Então, inicialmente, a gente não conseguia ter uma troca profissional (Licencianda C, P2).

Era muito clara a questão de "vocês não têm a prática, então vocês não sabem o que é ser professora". Nos primeiros seis meses a inflexibilidade foi total, mas no ano seguinte o modo de respeitar o nosso grupo mudou. Elas tiveram a chance de conhecer melhor o nosso trabalho e de reconhecer que ele era bom para os alunos e para elas também (Licencianda D, P2).

Nós tivemos problemas porque algumas professoras eram bem resistentes. Nos primeiros meses foram extremamente fechados. Elas pensam - $e$ algumas até dizem: "A gente trabalha assim há 10, 20, 25 anos e sempre deu certo, então não é você que vai chegar aqui e dizer que eu preciso mudar" (Licencianda E, P2).

Os depoimentos das licenciandas deixam clara a percepção de descrédito que as professoras manifestaram em relação ao trabalho desenvolvido por elas. Em parte, essa postura pode ser justificada pelo fato de também terem passado por situações semelhantes quando de suas atuações na condição de estagiárias. Nessa direção, uma das licenciandas complementa:

Nos viam como estagiárias dos anos 80 que chegavam, sentavam lá no fundo da sala de aula e observavam (Licencianda E, P2).

Não se está querendo dizer, porém, que as professoras sejam vilãs ou que elas 
resistam às propostas de mudança por uma escolha pessoal imprópria, pois se reconhece que sua resistência é derivada do receio a uma suposta invasão à autonomia profissional que possa comprometer de alguma forma as ações relacionadas ao desenvolvimento de suas aulas, respaldadas em seus saberes experienciais, conforme enfatiza Fernandes (2008) e endossa Scanfella (2013). Ou seja, constatamos que as professoras manifestaram resistência ao perceberem-se imersas em um conflito interno estabelecido mediante situações que, segundo Garrido e Carvalho (1999), mesclam as propostas de mudança, racionalmente aceitas, e seus saberes, interiorizados de forma espontânea a partir da vivência irrefletida.

Outro aspecto elencado sobre a resistência docente às operações de estagiários se traduz pelo que Guarnieri (2018) denomina como mensagens negativas. Tais mensagens, transmitidas pelos professores dos anos iniciais aos estagiários podem ser caracterizadas como desabafos, e geralmente se referem ao estresse diário decorrente da extensa jornada de trabalho, da falta de cooperação e reconhecimento da equipe gestora e do desprestígio e desvalorização social da profissão.

Das mensagens propaladas, a que mais se intensifica ao longo do tempo diz respeito à desvalorização da profissão. Pelo menos quatro licenciandas relataram na pesquisa da P2 que as professoras constantemente lhes diziam: "Por que você está aqui? É tão nova, é tão bonita! Ainda dá tempo de mudar de profissão, de apostar em algo mais rentável, pois como professora você vai ter que se conformar com baixos salários". O relato da licencianda D exprime sua sensação quanto a isso ao dizer que "Como se não bastasse elas serem desmotivadas, parece que queriam nos desmotivar também, porque elas ficavam o tempo todo 'destilando' mensagens negativas sobre a profissão".

Vale lembrar que a docência nos anos iniciais do ensino fundamental e na 
educação infantil, que corresponde à atuação do professor polivalente, detém ainda menos prestígio em relação à docência nos níveis mais elevados de ensino, que compete ao professor especialista. Gatti (2013) garante que essa diferenciação entre profissionais que pertencem à mesma categoria é repercutida na carreira, nos salários, nas representações da comunidade social, acadêmica e política. No entanto, ainda que as mensagens denotem o descontentamento dos professores em face das condições de trabalho - que, de fato, são problemáticas - elas podem:

[...] desestimular os futuros professores a optarem pela profissão conduzindo-os a se engajarem em atividades de pesquisas, sempre mais valorizadas na universidade, ou ainda, para aqueles que pretendem ser professores, alimentarem percepções e crenças de que basta gostar dos alunos, ter paciência, conviç̧ão e vocação que já possuem o suficiente para ser professor (GUARNIERI, 2018, p. 102).

Diante dessa dinâmica conflituosa, que tende a gerar insatisfação nos professores e falhas formativas para os estudantes, parece ser uma tática eficaz o que a licencianda A anuncia como 'ganhar a confiança da professora':

Até que tivéssemos representatividade demorou um tempo. Mas, acho que é o tempo normal, né? Porque tem que esperar para ganhar a confiança da professora, tem que mostrar que valoriza o trabalho dela, e que a gente não quer chegar atrapalhando tudo aquilo que ela organizou em seus anos de profissão (Licencianda A, P2).

O que o relato aponta parece ser pertinente, pois o estabelecimento de relações cordiais, além de favorecer a realização de atividades e garantir aberturas de espaço para a licencianda se desenvolver no domínio prático da formação, cria também mecanismos de socialização pré-profissional. Esse tipo de relação, acrescentam Tardif e Raymond (2000), desencadeia um processo de formação em que o licenciando aprende a entender as rotinas e práticas do trabalho docente, ao mesmo tempo em que recebe uma formação referente às regras e valores da organização escolar e ao 
significado que isto tem para as pessoas que praticam o ofício.

Assim, verificamos que na pesquisa da P2 também fica evidente a importância do saber ponderar/analisar/agir dos sujeitos que adentram o espaço escolar. E essa preparação precisa emergir na própria universidade, já que ela congrega os elementos necessários para o desenvolvimento de um amálgama de habilidades didáticas e comportamentais; para o entrelaçamento entre saber científico e saber da experiência, sempre balizado pelo contingente contextual; e para o estabelecimento de discussões que levem em consideração a aprendizagem de uma profissão (SOUZA; GUARNIERI, 2016; SOUZA; PASSALACQUA, 2019). Preparação essa que deve se estabelecer por meio de orientações dadas pelos professores que ministram as aulas de estágio supervisionado ou que coordenam programas institucionais de iniciação à docência.

\section{Considerações finais}

Retomando as análises empreendidas e as verificações encontradas, visualizamos um tema gerador de tensões na esfera da formação e do trabalho docente. Tema este que, inegavelmente, constitui-se como uma das facetas do processo de profissionalização do sujeito em formação, uma vez que apresenta elementos intrínsecos à atividade docente que se estabelecem há décadas, embora sejam pouco problematizados.

A título de inferência, mas sem o intuito de esgotar o assunto, ponderamos que a resistência docente é, de fato, uma tática de transgressão manifestada pelos professores perante as exigências cotidianas que nem sempre legitimam suas opiniões, saberes e experiências. Contudo, constatamos, também, que as atitudes resistentes 
não são irreversíveis, isto é, existem maneiras de se romper as posturas de inflexibilidade docente a partir da prática de valorização, respeito, adequação e compreensão do trabalho exercido pelos professores.

Mostrar ao professor a importância de sua atuação tanto como co-formador de futuros professores quanto como protagonistas de pesquisas acadêmicas que versam sobre a escola, os processos formativos, o trabalho docente e as práticas pedagógicas, são maneiras eficientes de agregar valor e reconhecimento às atividades que esses sujeitos realizam. Dessa forma, além de ratificarmos a hipótese cogitada inicialmente, apresentamos como pista para a superação ou minimização do problema em questão o exercício constante da alteridade e a destreza para o estabelecimento de olhares compreensíveis e atitudes diplomáticas. Consideração, pontualidade, iniciativa, gentileza e parceria devem mais do que meras palavras na relação que se estabelece no âmbito pedagógico. E, embora elas estejam mais atreladas a atitudes comportamentais do que a atitudes propriamente didáticas, representam elementochave para o estabelecimento de uma atmosfera mais harmoniosa e, consequentemente, mais produtiva na escola.

Ademais, faz-se relevante acrescentar que o papel da universidade é fundamental nesse processo de flexibilização da postura docente, uma vez que sua colaboração poderia munir os estagiários de uma visão adequada sobre a atuação no interior das escolas, bem como orientar o pesquisador a agir de maneira articulada e cooperativa. Isso sem mencionar os efeitos que poderiam ser incorporados aos futuros professores, a fim de que a cultura escolar, cuja idiossincrasia revela-se impregnada de individualismo, possa, gradualmente, incorporar o princípio da coletividade. 


\section{Referências}

BARDIN, Laurence. Análise de conteúdo. Tradução: Luís Antero Reto e Augusto Pinheiro. São Paulo: Edições 70, 2011.

CARVALHO, Maria Pinto de. Um lugar para o pesquisador na vida cotidiana da escola. In: ZAGO, Nadir; CARVALHO, Maria Pinto de; VILELA, Rita Amélia Teixeira (org.). Itinerários de pesquisa: perspectivas em sociologia da educação. Rio de Janeiro: DP\&A, 2003. p. 207-222.

FERNANDES, Maria José da Silva. A coordenação pedagógica em face das reformas escolares paulistas (1996-2007). 2008. 282 f. Tese (Doutorado em Educação Escolar) - Faculdade de Ciências e Letras, Universidade Estadual Paulista, Araraquara, 2008. Disponível em: https://repositorio.unesp.br/bitstream/handle/11449/101617/fernandes_mjs_dr_ar afcl.pdf?sequence=1\&isAllowed=y. Acesso em: 15 jan. 2020.

GARRIDO, Elsa; CARVALHO, Anna Maria Pessoa de. Reflexão sobre a prática e qualificação da formação inicial docente. Cadernos de Pesquisa, São Paulo, n. 107, p. 149-168, jul. 1999. Disponível em: http://www.scielo.br/scielo.php?pid=S010015741999000200006\&script=sci_abstract\&tlng=pt. Acesso em: 17 jan. 2019.

GATTI, Bernardete Angelina et al. (org.). Por uma política nacional de formação de professores. 1. ed. São Paulo: Editora Unesp, 2013.

GATTI, Bernardete Angelina. Formação de professores e carreira: problemas e movimento de renovação. Campinas: Autores Associados, 2000.

GATTI, Bernardete Angelina. Os professores e suas identidades: o desvelamento da heterogeneidade. Cadernos de Pesquisa, São Paulo, n. 98, p. 85-90, 1996. Disponível em: http://publicacoes.fcc.org.br/ojs/index.php/cp/article/view/798. Acesso em: 15 jan. 2019.

GATTI, Bernardete Angelina; BARRETO, Elba Siqueira de Sá (org.). Professores do Brasil: impasses e desafios. Brasília: UNESCO, 2009. 
GAUTHIER, Clermont et al. Por uma teoria da Pedagogia. Ijuí: Unijuí, 1998.

GUARNIERI, Maria Regina. Permanências e novos desafios da formação inicial: contribuições da didática e práticas de ensino na preparação de professores. In: MARIN, Alda Junqueira; PIMENTA, Selma Garrido (org.). Didática: teoria e pesquisa. 2. ed. Araraquara: Junqueira \& Marin; Ceará: UECE, 2018. p. 99-112.

HUBERMAN, Michael. O ciclo de vida profissional dos professores. In: NÓVOA, António (org.). Vidas de professores. Porto: Porto Editora, 2000. p. 31-61.

MARCELO, Carlos. Formação de professores para uma mudança educativa. PortoPortugal: Porto Editora, 1999.

PESSANHA, José Américo. Filosofia e modernidade: racionalidade, imaginação e ética. Educação \& Realidade, Porto Alegre, v. 22, n. 1, p. 13-32, jan./jun. 1997. Disponível em: https://seer.ufrgs.br/educacaoerealidade/article/view/71454. Acesso em: 15 jan. 2019.

PIMENTA, Selma Garrido. O estágio na formação de professores: unidade teoria e prática? 4. ed. São Paulo: Cortez, 2001.

SCANFELLA, Ana Teresa. Mudanças na alfabetização e resistência docente na "voz" de professoras dos anos iniciais do ensino fundamental: implicações das medidas políticas na prática pedagógica. 2013. 208 f. Dissertação (Mestrado em Educação Escolar) - Faculdade de Ciências e Letras, Universidade Estadual Paulista, Araraquara, 2013. Disponível em:

https://repositorio.unesp.br/bitstream/handle/11449/90120/scanfella_at_me_arafcl. pdf?sequence=1\&isAllowed=y. Acesso em: 14 jan. 2020.

SILVA JÚNIOR, João dos Reis; FERRETI, Celso João. $\mathbf{O}$ institucional, a organização e a cultura da escola. São Paulo: Xamã, 2004.

SOUZA, Nathália Cristina Amorim Tamaio de. As ações do PIBID pedagogia e suas relações com o preparo prático para a docência nos anos iniciais do ensino fundamental. 2014. 153 f. Dissertação (Mestrado Acadêmico em Educação Escolar) Universidade Estadual Paulista, Araraquara, 2014. Disponível em:

https://repositorio.unesp.br/bitstream/handle/11449/115750/000809893.pdf?seque nce=1\&isAllowed=y. Acesso em: 16 jan. 2020. 
SOUZA, Nathália Cristina Amorim Tamaio de; GUARNIERI, Maria Regina. O lugar da prática na formação inicial de professores: o conceito de preparo prático em contextos de inserção à docência no Brasil. Revista Ibero-Americana de Estudos em Educação: Araraquara, v. 11, n. 2, p. 625-643, abr./jun. 2016. Disponível em: https://periodicos.fclar.unesp.br/iberoamericana/article/view/8465. Acesso em: 17 jan. 2019.

SOUZA, Nathália Cristina Amorim Tamaio de; PASSALACQUA, Flávia Graziela Moreira. $O$ processo de construção da profissionalidade docente: aspectos concernentes à formação inicial. Revista Internacional de Educação Superior, Campinas, v. 5, e019018, p. 1-11, 2019. Disponível em:

https://periodicos.sbu.unicamp.br/ojs/index.php/riesup/article/view/8653296/0. Acesso em: 17 jan. 2019.

TARDIF, Maurice. Saberes docentes e formação profissional. Petrópolis: Vozes, 2002.

TARDIF, Maurice; RAYMOND, Danielle. Saberes, tempo e aprendizagem do trabalho no magistério. Educação \& Sociedade, Campinas, v. 21, n. 73, p. 209-244, 2000.

Disponível em: http://www.scielo.br/scielo.php?pid=S010173302000000400013\&script=sci_abstract\&tlng=pt. Acesso em: 25 fev. 2019.

TEDESCO, Juan Carlos. O novo pacto educativo: educação, competitividade e cidadania na sociedade moderna. São Paulo: Ática, 2007.

TURA, Maria de Lourdes Rangel. A observação no ambiente escolar. In: ZAGO, Nadir; CARVALHO, Maria Pinto de; VILELA, Rita Amélia Teixeira. Itinerários de pesquisa: perspectivas em sociologia da educação. Rio de Janeiro: DP\&A, 2003. p. 183-206.

Enviado em: 04/03/2019

Aprovado em: 17/06/2019 